\title{
Automated Computation of Leaf Area index from Fruit Trees using Improved Image Processing Algorithms Applied to canopy cover digital photograpies
}

\author{
Marco Mora $^{1,3^{*}}$, Marcos Carrasco-Benavides ${ }^{2,3}$ \\ ${ }^{1}$ Department of Computer Science, Universidad Católica del Maule, Talca, Chile \\ marcoantoniomoracofre@gmail.com \\ 2 Department of Agricultural Science, Universidad Católica del Maule, Curicó, Chile \\ cfredes@ucm.cl \\ ${ }^{3}$ Laboratory of Technological Research in Pattern Recognition, Avenida San Miguel 3605, \\ Talca, Chile \\ http://www.litrp.cl
}

Keywords: Leaf area index, Image analysis, Hand-held sensor, Canopy Cover

Leaf Area index (LAI) is a critical parameter in plant physiology for models related to growth, photosynthetic activity and evapotranspiration. It is also important for farm management purposes, since it can be used to assess the vigor of trees within a season with implications in water and fertilizer management. Among the diverse methodologies to estimate LAI, those based on cover photography are of great interest, since they are non-destructive, easy to implement, cost effective and have been demonstrated to be accurate for a range of tree species. However, these methods could have an important source of error in the LAI estimation due to the inclusion within the analysis of non-leaf material, such as trunks, shoots and fruits depending on the complexity of canopy architectures. This paper proposes a modified cover photography method based on specific image segmentation algorithms to exclude contributions from nonleaf materials in the analysis. Results from the implementation of this new image analysis method for cherry tree canopies showed a significant improvement in the estimation of LAI compared to ground truth data using allometric methods and previously available cover photography methods. The proposed methodological improvement is very simple to implement, with numerical relevance in species with complex 3D canopies where the woody elements greatly influence the total leaf area.

\footnotetext{
Acknowledgment: This presentation is financed by the research project FIC-R Maule 2017 "Desarrollo de un Equipo para la Estimación de la Calidad de la Frambuesa en base a Visión por Computador".
}

Publicado originalmente en: Marco Mora et al., "Automated Computation of Leaf Area index from Fruit Trees using Improved Image Processing Algorithms Applied to canopy cover digital photograpies", Computers and Electronics in Agriculture 123 (2016) 195-202.

https://doi.org/10.1016/j.compag.2016.02.011. 